\title{
Analysis of Clinical Effect of Acupuncture Combined with Massage on Congenital Muscular Torticollis
}

\author{
KUN JIA, HAI TIAN LI, Z. L. LV AND Y. YANG* \\ Department of Rehabilitation, Beijing Children's Hospital, Capital Medical University, National Center for Children's Health, \\ No. 56 Nanlishi Road, Xicheng District, Beijing 100045, China
}

Jia et al.: Effect of Acupuncture Combined with Massage on CMT

\begin{abstract}
To investigate the therapeutic effect and safety of acupuncture combined with massage method in the treatment of congenital muscular torticollis. 86 cases of children with congenital muscular torticollis admitted to our outpatient clinic from June 2016 to June 2020 were selected and randomly divided into 43 cases in the treatment group and 43 cases in the control group using the simple numerical table randomization method. The control group was treated with massage method, while the treatment group was treated with acupuncture method in combination with the control group. The changes of ultrasound characteristics, treatment effect and the angle of head deviation and passive neck mobility after treatment were compared and analyzed between the two groups. The results showed that the head deviation angle became smaller in both groups after treatment compared with that before treatment and the difference was statistically significant $(\mathbf{p}<\mathbf{0 . 0 5})$ and the difference between the head deviation angle before and after treatment in the treatment group was greater than that in the control group and the difference was statistically significant; color Doppler ultrasound dynamically observed the echogenicity of the muscle in the lesion area before and after treatment and found that there was a trend of homogenization. The difference in mass thickness was statistically significant $(p<0.05)$ when comparing the two groups before and after treatment and between groups after treatment. The difference in sternocleidomastoid contracture length was statistically significant $(\mathbf{p}<\mathbf{0 . 0 5})$ when comparing the two groups before and after treatment, and the difference in syndrome score was statistically significant $(p<0.01)$ when comparing the two groups before treatment; the difference in syndrome score before and after treatment was greater in the observation group than in the control group and the difference was statistically significant $(p<0.01)$. In conclusion, acupuncture combined with massage is an effective treatment for congenital muscular torticollis and it is a treatment method worthy of clinical promotion.
\end{abstract}

Key words: CMT, acupuncture, massage, clinical efficacy

Congenital muscular torticollis (CMT), is head tilting to the affected side due to contracture of one side of sternocleidomastoid (SCM). It is a common clinical disease in pediatrics ${ }^{[1]}$, the incidence is about $0.3 \%-1.9$ $\%{ }^{[2]}$, which has exceeded hip dislocation and clubfoot, ranking first among common childhood congenital musculoskeletal diseases ${ }^{[3-5]}$. If the disease is not detected early and treated in time, it may also lead to asymmetric development of the face and eye clefts, strabismus and even secondary cervical scoliosis, wedge deformation of the vertebral body, etc., which not only affects the appearance of the child, but may also impair children's mental health. Therefore, the early detection and early treatment of this disease is of great significance.

If the disease is treated with correct and effective non-surgical treatment early, most children can be completely cured. Currently, the treatment to this disease are main acupuncture, massage and surgery ${ }^{[6,7]}$. The surgical treatment has the anesthetic accident and the operation risk. Cervical massage has a certain effect on congenital torticollis mass or induration, but it has some limitations on the recovery of cervical mobility in the later stage ${ }^{[8]}$. Therefore, acupuncture combined with massage therapy for congenital torticollis has few side effects, positive curative effect and easy to be

*Address for correspondence

E-mail: yangzcdt08@163.com 
accepted by patients and their families. In recent years, acupuncture combined with massage has been used in our department to treat CMT, therapeutic effect and safety will be explores in this research.

\section{MATERIALS AND METHODS}

\section{General clinical data:}

A total of 86 children with CMT admitted to our hospital by the outpatient from June 2016 to June 2020 were selected and randomly divided into treatment group (43 cases) and control group (43 cases) according to the simple number table based on the treatment order. 6 cases among them were excluded, because they were not in accordance with the course of treatment, nor did they complete $1 / 2$ of the course of treatment and were not included in the efficacy statistics.

There was no significant difference in general data between the two groups of children $(\mathrm{p}>0.05)$, as shown in Table 1.

\section{Research standards}

\section{Diagnostic criteria:}

According to "Practical Pediatric Surgery", the diagnosis is confirmed based on medical history, clinical symptoms, signs and auxiliary examinations. Medical history, most of them have a history of breech delivery; symptoms, head is oblique to the side of the mass, some children with partial cephalic and facial asymmetry; physical signs, a bump that can be palpable at the sternocleidomastoid muscle; auxiliary examination, B ultrasonic diagnosis ${ }^{[9]}$.

Inclusion Criteria-Meet the diagnostic criteria of Western medicine; No other treatment after onset; Between 3 and 12 mo old; the family of the child knows the research content and the guardian signed the informed consent.

Exclusion criteria-Fail to meet the above inclusion criteria; Acquired spastic torticollis, bony torticollis,

TABLE 1: COMPARISON OF GENERAL DATA BETWEEN THE TWO GROUPS

\begin{tabular}{lccccccc}
\hline Group & Sex ratio & Age $(\mathrm{d})$ & Courses & \multicolumn{2}{c}{ Lesion location } & \multicolumn{2}{c}{ Lesion type } \\
\cline { 3 - 7 } (male/female) & Left side & $\begin{array}{c}\text { Right side } \\
\text { involvement }\end{array}$ & Mass & Non-mass \\
\hline Control group & $21 / 22$ & $190.75 \pm 31.50$ & $1.75 \pm 0.35$ & 22 & 21 & 26 & 17 \\
Therapy group & $20 / 23$ & $188.60 \pm 29.70$ & $1.72 \pm 0.27$ & 21 & 22 & 24 & 19 \\
$x^{2}$ & 0.149 & 0.257 & 0.227 & & 0.168 & 0.821 \\
$\mathrm{p}$ & 0.731 & 0.653 & 0.709 & 0.723 & 0.337 \\
\hline
\end{tabular}

neural torticollis, traumatic or visually induced torticollis; Severe lesions in the heart, liver, kidney or other important organs; The neck skin has broken and is not suitable for massage; Have received other relevant treatments, which may affect the results of this study or should not be admitted to this study according to the judgment of the researcher; Unwilling to sign the agreement.

Criteria for shedding- Children with severe adverse events, aggravation of the condition, special physiological changes or other unexpected conditions, which made them not suitable for further study; Patients with incomplete clinical data or patients who are spontaneously detached or lost contact during observation; Those who voluntarily withdraw during the trial for various reasons.

\section{Methods:}

The control group was treated with massage therapy and the main steps were as follows: step 1 pushing and rubbing: the doctor would hold the child on the leg, make the patient face to the doctor and push and rub the sternocleidomastoid muscle from top to bottom with the thumb, the frequency was 100-120 times per min and the operation time was about 5 min. Step 2 knead method: the same position as before, the doctor uses the thumb, the index finger and middle finger to repeatedly pinch the sternocleidomastoid muscle with relative force, the frequency is $100-120$ times per min and the operation time is about 5 min. Step 3 pulling method: the doctor holds the child on his lap so that he faces him, holds the head of the child with one hand, presses the shoulder of the child with the other hand, make child's head gradually towards the healthy side. Gradually stretch the sternocleidomastoid muscle of the affected side in the coronal position, to the extent that the child can tolerate it, not more than the normal physiological range. Hold each pull for 2-3 s and pull 20 times repeatedly. Step 4 rotations: the doctor holds the child on the leg, makes the patient face to himself, and asks the assistant to hold both shoulders.

The doctor places one hand on the head of the child and the other hand on the healthy side of the child's jaw and 
makes rotation, so that the affected side's jaw gradually approaches the affected side's shoulder. Elongate the sternocleidomastoid muscle on the affected side in sagittal position; the amplitude is from small to large, to the extent that the child can tolerate it, not more than the normal physiological range. After the above four steps are operated in sequence for one time, perform the first step of pushing and kneading again and change the operation time to $3 \mathrm{~min}$. Finally, lightly hold the shoulder and neck 5 times.

The treatment group was treated with acupuncture on the basis of the control group. The acupuncture method selected Fengchi, Wangu, Tianzhu, Renying, Futu, Tianchuang, Shuitu, and Tianding as the treatment points. After local disinfection, use disposable sterile acupuncture needles for rapid needle insertion, the depth of needle insertion is about $15 \mathrm{~mm}$, not retaining needle and the treatment is performed every other day.

\section{Observation indicators:}

For clinical symptoms and sternocleidomastoid muscle induration, perform ultrasound examinations before and after treatment to understand the location, thickness, shape and internal echo of the induration. High frequency two dimensional color Doppler ultrasound: The machine is a Philips HD11 color Doppler diagnostic instrument with a probe frequency of $10 \mathrm{MHz}$.

Head askew, as the main symptom of CMT, often associated with cervical activity range reduction (flexion to the healthy side or rotation to the affected side). Therefore, the deflection angle of the head, the passive flexion range of the healthy side of the neck and the passive rotation range of the affected side of the neck were used as the observation indicators, which were measured before and after the treatment.

According to the "Clinical Disease Diagnosis and Improvement Criteria for Cure", the formulation is as follows: Cure: the child's symptoms disappear completely or basically, the head and neck can be kept in a neutral position for a long time and they can rotate freely to both sides with a normal range of motion, bilateral symmetry, symptom score reduction $\geq 90 \%$; Effective: symptoms improved significantly in children, the head and neck can remain neutral for a short time, but they are used to being in a mild torticollis position $\left(<10^{\circ}\right)$ or the torticollis is significantly improved $\left(\geq 15^{\circ}\right)$ compared to before, the children can freely rotate to both sides, the range of motion is basically normal, the symptom score decreased $<90 \%$ and $\geq 30 \%$; Invalid: basically no improvement or symptom improvement is not obvious, symptom score decreases $<30 \%$.

Neck color Doppler ultrasound was used to observe the length change of sternocleidomastoid contracture.

\section{Statistical analysis:}

Statistical Package for the Social Sciences (SPSS) 20.0 was used for data collation and analysis. Measurement data was represented as $\mathrm{x} \pm \mathrm{s}$, intra group comparison before and after treatment was performed by paired T-test, inter group comparison by two independent sample T-test. Counting data were represented by composition ratio and rate, and the ratio of inter-group rate was compared by $\chi^{2}$ test. $\mathrm{p}<0.05$ was statistically significant.

\section{RESULTS AND DISCUSSION}

After treatment, the total effective rate in clinical of the treatment group and the control group were $93.02 \%$ and $72.09 \%$, respectively. The clinical efficacy of the two groups was significantly different, with statistically significant difference, as shown in Table 2.

The results showed that, compared with before treatment, the head deflection angle of both groups decreased after treatment, and the difference was statistically significant $(\mathrm{p}<0.05)$, indicating that treatment of both groups could effectively improve the head deflection symptoms of children. Compared with the control group, the difference between the treatment group's head deflection angle before and after treatment was greater than that of the control group and the difference was statistically significant $(\mathrm{p}<0.01)$, indicating that the treatment group has more advantages in improving the children's head deflection angle, see details in Table 3.

TABLE 2: COMPARISON OF THERAPEUTIC EFFECTS BETWEEN THE TWO GROUPS

\begin{tabular}{lcccccc}
\hline Group & Cases & Cure & $\begin{array}{c}\text { Significantly } \\
\text { effective }\end{array}$ & Effective & Invalid & $\begin{array}{c}\text { Total effective } \\
\text { rate }\end{array}$ \\
\hline Control group & 43 & 6 & 14 & 11 & 12 & $72.09 \%$ \\
Treatment group & 43 & 13 & 21 & 6 & 3 & $93.02 \%$ \\
$x^{2}$ & - & 4.283 & 1.351 & 2.919 & 8.183 & 4.759 \\
$\mathrm{p}$ & - & 0.001 & 0.213 & 0.001 & 0.001 & 0.001 \\
\hline
\end{tabular}


TABLE 3: COMPARISON OF HEAD DEFLECTION ANGLE AND NECK PASSIVE RANGE OF MOTION BEFORE AND AFTER TREATMENT BETWEEN THE TWO GROUPS

\begin{tabular}{|c|c|c|c|c|c|c|c|}
\hline \multirow[b]{2}{*}{ Group } & \multirow[b]{2}{*}{ Cases } & \multicolumn{3}{|c|}{ Head deflection angle } & \multicolumn{3}{|c|}{ Neck passive range } \\
\hline & & $\begin{array}{c}\text { Before } \\
\text { treatment }\end{array}$ & $\begin{array}{c}\text { After } \\
\text { treatment }\end{array}$ & Difference & $\begin{array}{c}\text { Before } \\
\text { treatment }\end{array}$ & $\begin{array}{c}\text { After } \\
\text { treatment }\end{array}$ & Difference \\
\hline Control group & 43 & $13.25 \pm 3.15$ & $6.48 \pm 3.26$ & $6.77 \pm 3.07$ & $67.25 \pm 8.85$ & $74.15 \pm 9.44$ & $6.90 \pm 1.23$ \\
\hline $\begin{array}{l}\text { Treatment } \\
\text { group }\end{array}$ & 43 & $12.56 \pm 3.72$ & $8.52 \pm 4.15$ & $4.04 \pm 1.16$ & $68.65 \pm 6.75$ & $82.33 \pm 6.16$ & $11.68 \pm 2.44$ \\
\hline$x^{2}$ & - & 1.053 & 4.235 & 3.560 & 1.125 & 6.432 & 7.058 \\
\hline $\mathrm{p}$ & - & 0.124 & 0.001 & 0.001 & 0.213 & 0.001 & 0.001 \\
\hline
\end{tabular}

Color Doppler ultrasound was used to dynamically observe the echoes of the muscles before and after treatment in the lesion area and it was found that there was a trend of homogenization. There were statistically significant differences in mass thickness in both of the two groups before and after treatment and intra-group comparison after treatment $(\mathrm{p}<0.05)$. Comparison of the two groups before and after treatment and between the groups after treatment, the difference in the length of sternocleidomastoid muscle contracture was statistically significant $(\mathrm{p}<0.05)$, as shown in Table 4 for details.
The results showed that compared with before treatment, the symptom scores of the two groups decreased after treatment and the difference was statistically significant $(p<0.01)$, indicating that the two treatments can effectively improve the clinical symptoms of children; Compared with the control group, the difference of symptom score before and after treatment in the observation group is greater, which is with statistically significant difference $(p<0.01)$, indicating that the observation group had more advantages in improving the clinical symptoms of children, as shown in Table 5.

TABLE 4: COMPARISON OF ULTRASOUND IMAGE CHARACTERISTICS BETWEEN THE TWO GROUPS

\begin{tabular}{|c|c|c|c|c|c|c|c|}
\hline \multirow{2}{*}{ Group } & \multirow{2}{*}{ Cases } & \multicolumn{3}{|c|}{ Mass thickness (mm) } & \multicolumn{3}{|c|}{$\begin{array}{l}\text { Length of sternocleidomastoid muscle } \\
\text { contracture }(\mathrm{mm})\end{array}$} \\
\hline & & $\begin{array}{c}\text { Before } \\
\text { treatment }\end{array}$ & $\begin{array}{c}\text { After } \\
\text { treatment }\end{array}$ & Difference & $\begin{array}{c}\text { Before } \\
\text { treatment }\end{array}$ & $\begin{array}{c}\text { After } \\
\text { treatment }\end{array}$ & Difference \\
\hline $\begin{array}{l}\text { Treatment } \\
\text { group }\end{array}$ & 43 & $11.53 \pm 2.31$ & $6.09 \pm 1.40$ & $5.44 \pm 1.82$ & $11.40 \pm 2.10$ & $4.70 \pm 1.40$ & $6.70 \pm 1.58$ \\
\hline Control group & 43 & $11.69 \pm 2.22$ & $8.20 \pm 1.50$ & $3.49 \pm 1.16$ & $11.82 \pm 2.33$ & $8.20 \pm 1.50$ & $3.62 \pm 1.26$ \\
\hline$x^{2}$ & - & 1.053 & 4.235 & 3.560 & 1.125 & 6.432 & 7.058 \\
\hline $\mathrm{p}$ & - & 0.124 & 0.001 & 0.001 & 0.213 & 0.001 & 0.001 \\
\hline
\end{tabular}

TABLE 5: COMPARISON OF SYMPTOM SCORES BETWEEN THE TWO GROUPS BEFORE AND AFTER TREATMENT

\begin{tabular}{lcccc}
\hline \multirow{2}{*}{ Group } & Cases & \multicolumn{3}{c}{ Symptom score } \\
\cline { 3 - 5 } & & Before treatment & After treatment & Difference \\
\hline Treatment group & 43 & $17.69 \pm 4.62$ & $5.38 \pm 5.90$ & $12.31 \pm 3.67$ \\
Control group & 43 & $18.00 \pm 5.25$ & $10.93 \pm 6.92$ & $7.07 \pm 4.70$ \\
$\mathrm{x}^{2}$ & - & 1.053 & 4.235 & 4.608 \\
$\mathrm{p}$ & - & 0.124 & 0.001 & 0.001 \\
\hline
\end{tabular}


CMT is a syndrome in which the head is tilted to the affected side due to the tense contracture of one side sternocleidomastoid muscle and the face rotates to the healthy side ${ }^{[3]}$. Retrieving ancient documents, Chinese medicine does not have a corresponding name for this disease, but many physicians classify this disease into the categories of "sinew contraction", "sinew knot" and "sinew spasm", so the disease is closely related to sinew. Shuo Wen said: "sinew, the strength of the flesh, bamboo, is a thing full of sinew, pointing out that the sinew can produce power and sinew is a kind of meat tissue. In this disease "sinew" mainly refers to muscle and tendon tissue, "sinew contraction", "sinew knot" and "sinew spasm", both have the meaning of tendon contracture, which can't extend. The principle of CMT treatment is mainly to dredge the meridians, relieve the yang and relax the tendons and dispel blood stasis. Massage has the functions of dredging the meridians, promoting qi and activating blood. By means of manual operation which can convert mechanical energy into heat energy, CMT plays roles of capillary expansion, accelerating the blood circulation, improving local blood supply and nutrition metabolism of the skin and muscle tissue, restraining fiber hyperplasia, slowing even reversing the muscle fiber to change, relieving muscle contracture ${ }^{[10-13]}$. Dredging the meridians is the most important and direct effect of acupuncture and moxibustion ${ }^{[14]}$. Huangdi Neijing called it "untying the knot" by using acupuncture and moxibustion to dredge the meridians. Modern studies have shown that acupuncture can provide a certain amount of stimulation to the fascia and the connective tissue around the lesion, generate neurobiological information of deep sensation and then transmit it to the brain center, which can reflexively regulate the muscular tension around the lesion ${ }^{[15]}$. Acupuncture can also compress the capillaries and lymphatic vessels in the local connective tissue, accelerate the blood circulation and lymph circulation and improve the microcirculation of the diseased part through the mechanical pulling effect on the stimulated $\operatorname{part}^{[16]}$.

This study mainly used four massage manipulations: push-kneading method, drawing method, pulling method and rotating method. The steps are pushing and kneading, drawing, pulling and rotating in sequence. After two cycles of operation, another acupuncture operation is completed. Preliminary pushing and rubbing can promote the blood circulation of the diseased part, improve the nutritional supply of skin and muscle, decompose adhesion, promote the absorption of mass and eliminate the swelling and contracture ${ }^{[17]}$.

This operation is gentle, which makes it easy for children to adapt and accept the next manipulation at the beginning of treatment. After the muscles are relaxed to a certain level, the application of pull and stretch method can relieve tendon knot to balance the bilateral head and neck muscles ${ }^{[18]}$. After the above two steps create good muscle conditions, you can use the stretching method and rotation. After the above two steps creating good muscle conditions, the traction and rotation method can be used. The traction method can effectively lengthen the sternocleidomastoid muscle fibers of the affected side, loosen adhesions, restore muscle elasticity, and improve muscle atrophy. Subsequent rotation technique can make the sternocleidomastoid muscle extended to the maximum within a safe range, counteract the deformity caused by the sternocleidomastoid contracture, improve muscle coordination and restore physiology muscle strength balance. After one operation in turn, the muscular condition of the children has risen to a certain level and then the operation is repeated in sequence, which made the muscle further improved from a higher starting point. At last, self-weight traction was used to end the massage and proper traction was used to balance muscle groups and relax the body and mind of children.

At last, self-weight traction was used to end the massage and proper traction was used to balance muscle groups and relax the body and mind of children. These five methods are related to each other and proceed step by step. Each step lays the foundation for the next step, randomly disrupting the sequence or reversing the operation are not allowed, otherwise, it is easy to cause discomfort and crying in children, affect the efficacy and even aggravate sternocleidomastoid contracture.

Therefore, this method puts special emphasis on the initial muscle relaxation, the sinew-stretching is step by step, pushing and kneading and drawing, pulling and rotating follow the trend. Each step lays the foundation for the next step. Then traction is with children's own gravity, end with a needle method, it can be described as step by step, the process is clear; which can be described as progressive and clear; Especially during the operation, "Relieve the tendons $\rightarrow$ stretch the tendons $\rightarrow$ relax the tendons again $\rightarrow$ re-stretch the tendons", which seems to be repeated, but a circulation in fact, link to link, step to step.

This treatment have effects of relaxing the muscles and activating the blood, moderating the tendons and 
slowing down those urgent, softening the firm and loosening the knot, it can effectively relieve the tension and contracture of the neck muscles in children, which is a comprehensive treatment plan for CMT with simple operation and obvious characteristics. This study showed that the total effective rate in children in the treatment group was $95 \%$ and that in the control group was $75 \%$. The difference between the two groups was statistically significant $(p<0.05)$. The therapy course used in the treatment group was significantly shorter than the control group $(\mathrm{p}<0.05)$. Color Doppler ultrasonography showed differences in mass thickness and contracture length of sternocleidomastoid muscle between the two groups, all of which showed statistical significance $(p<0.05)$. Compared with before treatment, the head deviation Angle of both groups decreased after treatment and the difference was statistically significant $(p<0.05)$, indicating that the treatment of both groups could effectively improve the symptoms of head deviation of children.

Compared with the control group, the difference between the treatment group's head deflection angle before and after treatment was larger than that of the control group and the difference was statistically significant $(p<0.01)$, indicating that the treatment group has more advantages in improving the children's head deflection.

In summary, acupuncture combined with massage has a definite therapeutic effect on CMT, which is worthy of clinical promotion.

\section{Acknowledgement:}

This work was supported by the Beijing Children's Hospital, Capital Medical University, Zhong Li Lv and Yan Yang was considered as co-corresponding authors in our paper.

\section{Conflict of interests:}

The authors declared no conflict of interest.

\section{REFERENCES}

1. Cheng JC, Tang SP, Chen TM, Wong MW, Wong EM. The clinical presentation and outcome of treatment of congenital muscular torticollis in infants - a study of 1,086 cases. J Pediatr Surg 2000;35(7):1091-6.

2. Carenzio G, Carlisi E, Morani I, Tinelli C, Barak M, Bejor M, et al. Early rehabilitation treatment in newborns with congenital muscular torticollis. Eur J Phys Rehabil Med 2015;51(5):539-45.

3. Nichter S. A clinical algorithm for early identification and intervention of cervical muscular torticollis. Clin Pediatr 2016;55(6):532-6.
4. Suhr MC, Oledzka M. Considerations and intervention in congenital muscular torticollis. Curr Opin Pediatr 2015;27(1):75-81.

5. von Heideken J, Green DW, Burke SW, Sindle K, Denneen $\mathrm{J}$, Haglund-Akerlind $\mathrm{Y}$, et al. The relationship between developmental dysplasia of the hip and congenital muscular torticollis. J Pediatr Orthop 2006;26(6):805-8.

6. Davids JR, Wenger DR, Mubarak SJ. Congenital muscular torticollis: sequela of intrauterine or perinatal compartment syndrome. J Pediatr Orthop 1993;13(2):141-7.

7. Seyhan N, Jasharllari L, Keskin M, Savac1 N. Efficacy of bipolar release in neglected congenital muscular torticollis patients. Musculoskelet Surg 2012;96(1):55-7.

8. Lee IJ, Lim SY, Song HS, Park MC. Complete tight fibrous band release and resection in congenital muscular torticollis. J Plast Reconstr Aesthet Surg 2010;63(6):947-53.

9. Chen CE, Ko JY. Surgical treatment of muscular torticollis for patients above 6 years of age. Arch Orthop Trauma Surg 2000;120(3-4):149-51.

10. Stellwagen L, Hubbard E, Chambers C, Jones KL. Torticollis, facial asymmetry and plagiocephaly in normal newborns. Arch Dis Child 2008;93(10):827-31.

11. Nichter S. A clinical algorithm for early identification and intervention of cervical muscular torticollis. Clin Pediatr 2016;55(6):532-6.

12. Suhr MC, Oledzka M. Considerations and intervention in congenital muscular torticollis. Curr Opin Pediatr 2015;27(1):75-81.

13. Chen MM, Chang HC, Hsieh CF, Yen MF, Chen TH. Predictive model for congenital muscular torticollis: analysis of 1021 infants with sonography. Arch Phys Med Rehabil 2005;86(11):2199-203.

14. Best T M, Gharaibeh B, Huard J. Stem cells, angiogenesis and muscle healing: a potential role in massage therapies? Postgrad Med J 2013;89(1057):666-670.

15. Kaplan SL, Coulter C, Fetters L. Physical Therapy Management of Congenital Muscular Torticollis: An Evidence-Based Clinical Practice Guideline. FROM THE SECTION ON PEDIATRICS OF THE AMERICAN PHYSICAL THERAPY ASSOCIATION. Pediatr Phys Ther 2013;25(4):348-94.

16. Losee JE, Mason AC. Deformational plagiocephaly: diagnosis, prevention and treatment. Clin Plast Surg 2005;32(1):53-64.

17. Lee K, Chung E, Koh S, Lee BH. Outcomes of asymmetry in infants with congenital muscular torticollis. J Phys Ther Sci 2015;27(2):461-4.

18. Do TT. Congenital muscular torticollis: current concepts and review of treatment. Curr Opin Pediatr 2006;18(1):26-9.
This is an open access article distributed under the terms of the Creative Commons Attribution-NonCommercial-ShareAlike 3.0 License, which allows others to remix, tweak, and build upon the work non-commercially, as long as the author is credited and the new creations are licensed under the identical terms
This article was originally published in a special issue,
"Evolutionary Strategies in Biomedical Research and
Pharmaceutical Sciences" Indian J Pharm Sci 2021:83(3)spl
issue; $88-93$ 